\title{
23andMe's designer baby patent
}

Notwithstanding its troubles with the US Food and Drug Administration (p. 1), directto-consumer genetics company 23 andMe has been courting more controversy with the award in September of a 'designer baby' patent. This patent (US 8,543,339), entitled "Gamete donor selection based on genetic calculations" potentially offers a means for couples in fertility clinics to opt for traits in their offspring. It follows another controversial patent, awarded to 23 andMe in 2012, for variants associated with susceptibility for Parkinson's disease ('Polymorphisms associated with Parkinson's disease'; US 8,187,811). The data for these US patents are generated from 23andMe's customer base. As the company attempts to navigate the ethical minefields related to its use of personal health information and patenting of data, a question surfaces, Is 23 andMe doing research or business?

The 'designer baby' patent describes an "Inheritance Calculator" for using genotypic information from donors and recipients to compute the probability of observing particular phenotypes, from eye color to predisposition to cancer. Sigrid Sterckx, professor of ethics at Ghent University in Belgium, considers the donor selection method to amount to an "instrumentalization of both babies and reproductive partners, promoting a 'check-list' approach to viewing other human beings." Whereas all patent laws contain morality provisions, they are rarely applied by the US Patent and Trademark Office (USPTO). "There is case law from the nineteenth century in the United States to the effect that US patents should not be granted for inventions the use of which is contrary to 'sound morals' [(see Bedford v. Hunt (CCD Mass. 1817) for example)], but this aspect of the 'utility' requirement under US patent law nowadays unfortunately appears to be largely ignored," she says.

Dietrich Stephan, founder of personal genomics company Navigenics (which was acquired by Life Technologies in 2012) and Silicon Valley Biosystems, and now chairman of the department of human genetics at the University of Pittsburgh, sees the patent as "heretical." Already technologies like pre-implantation genetic diagnosis are being used to avoid having children with horrible diseases. "So what is a horrible disease? Is a horrible disease a child dying a year after birth? Is a horrible disease deafness? Or not being a basketball player?" he asks. Where you draw the line, according to Stephan is

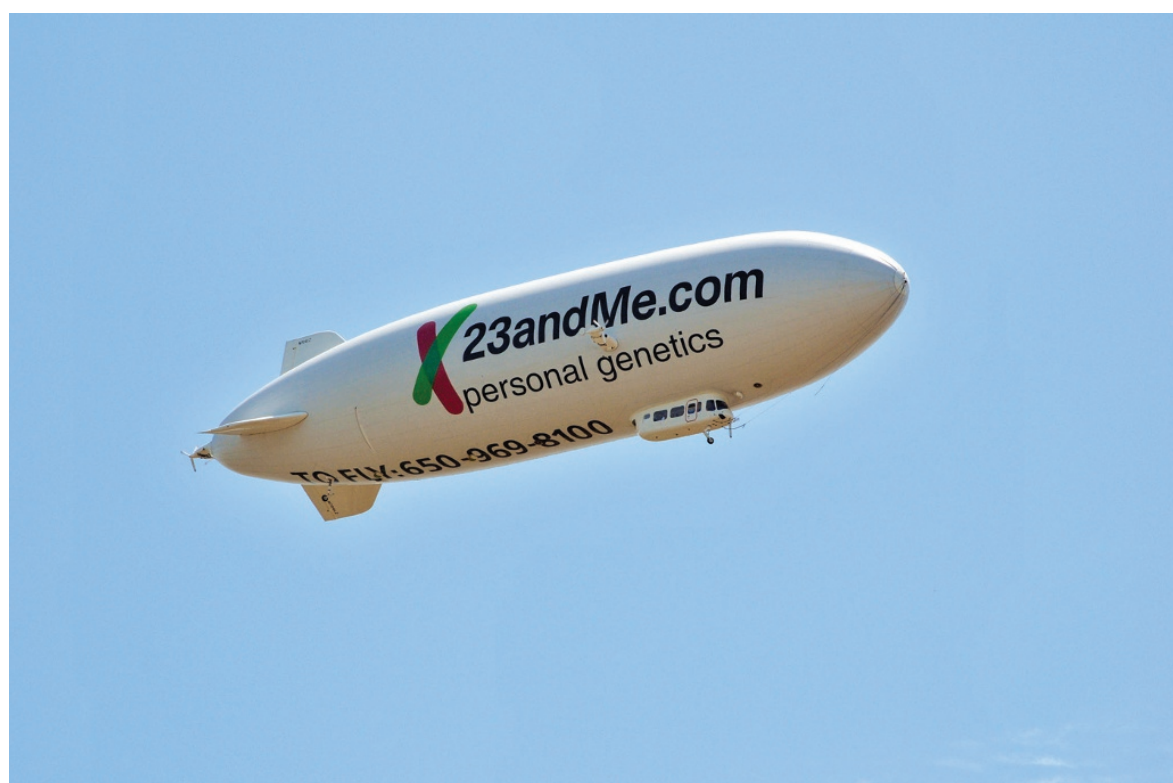

A Zeppelin carries advertising for the personal genetics company 23andMe. The company now faces stricter regulatory oversight.

normal quantitative traits, like intelligence and appearance.

On the other hand, using health information in a commercial setting could accelerate the understanding of the biology underlying genetic factors and disease susceptibility. Hank Greely, professor of law at Stanford University in California, sees this blurring of the lines between commerce and research by 23 andMe presaging things to come. Having electronic health records from millions of patients along with whole-genome sequences is potentially world-changing. "It will be so irresistible, I predict [society] won't be able to resist it. The issue with 23 andMe [patenting activity] is one early version of what is going to be a very large question," he says.

The Parkinson's disease patent covers methods for determining whether individuals carry a particular constellation of single-nucleotide polymorphisms (SNPs) and for generating a prognosis of susceptibility to Parkinson's based on these SNPs along with family medical and health data provided by the individuals. A less well-known aspect of the case brought against Salt Lake City, Utah-based Myriad Genetics for its $B R C A 1$ and BRCA2 patents puts this patent in doubt, according to John Conley, an intellectual property and biotech expert at the University of North Carolina in Chapel
Hill. In 2011, the US Court of Appeals for the Federal Circuit on the case of Association for Molecular Pathology versus Myriad Genetics invalidated both Myriad's composition of matter claim (later taken up and upheld in part by the US Supreme Court) and also a methods claim, which was not taken up by the Supreme Court and hence stands to this day. "[The 23andMe patent] is a pretty broad method patent. It covers analyzing the significance of a particular SNP, however you might do that. Myriad's federal circuit decision casts some doubt on that," he says.

According to Stanford's Greely, the Parkinson's patent raises a broader question concerning the use of people's health information and DNA for research of any kind and particularly for commercial research. "How much do [the customers] have to know, have agreed or have consented [to]. Our normal position has been you have to give informed consent. In this brave new world, it's not entirely clear that it's true," he says. 23andMe CEO Anne Wojcicki claims that the company's posted terms and conditions clearly indicate an intent to commercialize the information the company is gathering. Yet Greely finds this argument wanting. "The fact is that informed consent is different from checking a box that is linked to something nobody will ever read," he says.

Laura DeFrancesco Senior Editor 